\title{
0 desempenho dos alunos da Fundação Bradesco: uma comparação com os resultados do Saeb
}

RUBEN KLEIN*

NILMA FONTANIVE**

ANA LUISA RESTANI***

MARIA CRISTINA TELLES****

\section{RESUMO}

O artigo discute os resultados da avaliação dos alunos das escolas mantidas pela Fundaçáo Bradesco. Foram avaliados alunos do $5^{\circ}$ ano $/ 4^{a}$ série, $9^{\circ}$ ano $/ 8^{a}$ série do Ensino Fundamental e da $3^{a}$ série do Ensino Médio, em Língua Portuguesa e em Matemática. Os resultados dos alunos foram colocados nas escalas do Saeb graças à cessão pelo Instituto Nacional de Estudos e Pesquisas Educacionais Anísio Teixeira - Inep, de itens de teste aplicados na Prova Brasil e no Saeb. O desempenho dos alunos da Fundação Bradesco é muito superior, cerca de 1 desvio padrão, à média do Brasil, tanto em Matemática quanto em Língua Portuguesa, em todas as séries avaliadas. Quando comparado com os resultados das escolas particulares, o desempenho dos alunos da Fundação Bradesco é cerca

* Consultor da Fundação Cesgranrio (ruben@predialnet.com.br).

** Coordenadora de Avaliação da Fundação Cesgranrio (nilmaf@cesgranrio.org.br).

*** Superintendente Executiva da Fundação Bradesco (arestani@fundacaobradesco.org.br).

**** Gerente do Departamento de Educação Básica da Fundaçáo Bradesco (atelles@fundacaobradesco.org.br). 
de 10 pontos maior - 20\% do desvio padrão - na $4^{a}$ série, em Matemática e Língua Portuguesa, equivalente em ambas as disciplinas na $8^{a}$ série, e em Língua Portuguesa, na $3^{a}$ série do EM. Utilizando o índice do critério Brasil como medida do nível socioeconômico, encontrou-se que cerca de $55 \%$ dos alunos do $5^{\circ}$ e do $9^{\circ}$ ano estáo nas classes $\mathrm{C}, \mathrm{D}$ e E, enquanto na $3^{\mathrm{a}}$ série do $\mathrm{EM}$ esse porcentual é de $65 \%$. A maioria dos alunos de todas as séries, entretanto, pertence à classe $\mathrm{C}$. Palavras-chave: avaliação da educação, Bradesco, Ensino Fundamental, Ensino Médio.

\section{RESUMEN}

El artículo discute los resultados de la evaluación de los alumnos de las escuelas subsidiadas por la Fundación Bradesco. Fueron evaluados alumnos de $5^{o}$ año $/ 4^{a}$ serie, $9^{o}$ año $/ 8^{a}$ serie de la enseñanza fundamental y del $3^{\circ}$ año de la enseñanza media, en Lengua Portuguesa y Matemática. Los resultados fueron colocados en las escalas del Saeb gracias al permiso otorgado por el Instituto Nacional de Estudios y Encuestas Anísio Teixeira (Inep), para el uso de items de tests aplicados en la Prueba Brasil y en el Saeb. El desempeño de los alumnos de la Fundación Bradesco es bastante superior, cerca de 1 desviación estándar, de la media de Brasil, tanto en Matemática como en Lengua Portuguesa en todas las series evaluadas. Cuando se los compara con los resultados de las escuelas particulares, el desempeño de los alumnos de la Fundación Bradesco es cerca de 10 puntos mayor - un $20 \%$ de la desviación estándar - en la $4^{a}$ serie en Matemática y Lengua Portuguesa y equivalente en ambas asignaturas en la $8^{a}$ serie y en Lengua Portuguesa en el $3^{\circ}$ año de la Enseñanza Media. Utilizando el índice del criterio Brasil como medida del nivel socioeconómico, se constató que cerca de un $55 \%$ de los alumnos del $5^{\circ}$ y $9^{\circ}$ año están en las clases $\mathrm{C}$, D y E; mientras que en el $3^{\circ}$ año de la Enseñanza Media este porcentaje es de 65\%. La mayoría de los alumnos de todas las series, sin embargo, pertenece a la clase C.

Palabras clave: evaluación de la educación, Bradesco, enseñanza fundamental, enseñanza media.

\section{ABSTRACT}

This article discusses the evaluation results of students at the schools funded by Foundation Bradesco. The evaluation focused on 5th year/4th grade, 9th year/8th grade elementary school students and 3rd grade (senior year) high school students, in Portuguese and Mathematics. The student results were put on Saeb's scale thanks to Inep (Anísio Teixeira National Institute of Educational Studies and Research), which made available items of the tests applied at the Prova Brasil (Brazil Test) and Saeb. The Foundation Bradesco students' performance is much higher, approximately 1 standard deviation, from Brazil's average, both in Mathematics and in Portuguese in all the grades evaluated. When compared with the results of private schools, Foundation Bradesco students' performance is approximately 10 points higher -20 percent of standard deviation, in the 4th grade in Mathematics and Portuguese, and equivalent in both disciplines in the 8th grade, and in Portuguese in the senior year of high school. Using the index of the Brazil criterion as a measurement of their socio-economic level, we found that circa 55 percent of the 5th and 9th years students belong to classes $\mathrm{C}, \mathrm{D}$, and $\mathrm{E}$, while at the senior year this percentage is 65 percent. Most students is all grades, however, belong to class C.

Keywords: evaluation of education, Bradesco, elementary school, middle school. 


\section{APRESENTAÇÃO}

Nas últimas décadas, a avaliação vem despertando crescente interesse nos sistemas educativos de vários países. A partir de 1985, muitos deles criaram programas de avaliação de seus sistemas de ensino, valorizando a avaliação como ferramenta nos processos de gestão e na implementação de ações educativas.

A Fundaçáo Bradesco, desde 2001, integrada nesse contexto e a constante preocupação com a qualidade da educação que vem sendo praticada nas suas unidades escolares, adota um processo de avaliação da aprendizagem de seus alunos.

Com a instalaçáo da primeira unidade escolar, em 29 de junho de 1962, na cidade de Osasco/Sáo Paulo, iniciou-se um grande projeto educacional: o de atender populaçóes economicamente desfavorecidas e desprovidas dos mais elementares serviços de assistência, num período em que não se imaginavam expressóes como "terceiro setor" ou "responsabilidade social". Esse projeto concretizou-se em 2003, quando a Fundação Bradesco somou 40 unidades escolares, instaladas nos 26 Estados da federação e no Distrito Federal, localizadas, essencialmente, nas áreas em que se concentra seu público-alvo. Para cumprir sua missão, a Fundação Bradesco oferece à sua clientela: Educação Básica, Educação de Jovens e Adultos e Educação Profissional, em cursos presenciais e a distância.

A previsão de atendimento em 2008 é de 110.415 alunos, sendo 49.534 da Educação Básica. O orçamento anual deste ano é de R\$220.069.400,00.

Pode-se dizer que a Fundação Bradesco, ao longo de sua existência, buscou atender às exigências de cada momento histórico, mantendo o seu propósito de oferecer ensino gratuito e de boa qualidade a crianças, jovens e adultos em condiçóes economicamente desfavorecidas.

Atualmente, a Fundaçáo Bradesco, tendo seu projeto concretizado (o de instalar-se em cada um dos Estados da Federação), assume a missão de atuar como pólo gerador e multiplicador de educação e cultura e legitimar a Organização Bradesco como empresa socialmente responsável.

A Educação Básica, nas escolas da Fundação Bradesco, tem duração de 13 anos e compreende a Educação Infantil, o Ensino Fundamental (de 9 anos) e o Ensino Médio. A organização curricular desses níveis de ensino é norteada pela Lei de Diretrizes e Bases da Educação Nacional - LDB, Lei n. 9.394/96 e demais documentos oficiais que apresentam orientaçóes curriculares. A seleção dos alunos segue os critérios de: proximidade da residência em relaçáo à escola e menor renda familiar. Hoje são 1.147 professores, sendo 419 Professores Nível I e 728 Professores Nível II, com tempo médio de 7,5 anos de trabalho na Fundação Bradesco. 
O Ensino Fundamental, com duração de nove anos, objetiva a formação básica do cidadão, tendo como meios principais o pleno domínio da leitura, da escrita e do cálculo, visando à aquisição de conhecimentos científico-tecnológicos, relacionando a teoria com a prática em cada componente curricular, a formaçáo ética e o desenvolvimento da autonomia intelectual e do pensamento crítico. E, finalmente, o Ensino Médio, com duração de três anos, tem como finalidades a consolidação e o aprofundamento dos conhecimentos e valores adquiridos no Ensino Fundamental pelo educando, possibilitando a continuação de estudos, em níveis superiores, a preparação básica para o trabalho e o efetivo exercício da cidadania.

Atualmente, na Educação Básica são atendidos 43.155 alunos, sendo: 14.047 alunos ( $1^{\circ}$ ao $5^{\circ}$ ano); 16.209 ( $6^{\circ}$ ao $9^{\circ}$ ano) e 12.899 (Ensino Médio). Considerando que a experiência de Avaliação de Desempenho dos Alunos da Fundação Bradesco contemplou os alunos deste nível de educação, convém destacar alguns indicadores educacionais, entre eles:

- $1^{\circ}$ ao $5^{\circ}$ ano: Aprovados $=96,98 \%$

- $\sigma^{\circ}$ ao $9^{\circ}$ ano: Aprovados = 96,27\%

- Ensino Médio: Aprovados = 96,92\%

- Total Geral de Aprovação: 94,22\%

- $\quad$ Total de Evasão: 2,57\%

Este trabalho reúne as principais informaçóes sobre o desempenho dos alunos matriculados nas 43 escolas da Fundação Bradesco, distribuídas por todo o território nacional. Serão apresentados também dados sobre a abrangência da avaliação e uma breve descriçáo dos instrumentos utilizados.

\section{CARACTERÍSTICAS GERAIS DA AVALIAÇÃO}

As séries escolhidas para participarem da avaliação foram as mesmas do Saeb, ou seja, $5^{\circ}$ e $9^{\circ}$ anos do EF de 9 anos e $3^{\text {a }}$ série do EM, e as disciplinas Língua Portuguesa e Matemática.

A escolha dessas séries e disciplinas foi feita em função do interesse em avaliar os desempenhos dos alunos das escolas da Fundação Bradesco tomando como referência o desempenho dos alunos brasileiros, obtidos na Prova Brasil e no Saeb 2005.

$\mathrm{Na}$ procura de fatores intra e extra escolares que possam estar associados aos desempenhos alcançados nas provas, foram aplicados questionários a alunos, professores das disciplinas e turmas avaliadas e também aos diretores das escolas. 
Para compor os instrumentos da avaliação, foram selecionados itens de teste do banco nacional de itens do Saeb (BNI) e questóes abordando variáveis demográficas, socioeconômicas e culturais dos alunos, professores e gestores retiradas dos questionários aplicados pelo Saeb 2003/Prova Brasil 2005.

Os cadernos de teste apresentaram 30 questóes de Língua Portuguesa e 30 questóes de Matemática para os alunos de $5^{\circ}$ ano, e 39 questóes para o $9^{\circ}$ ano e $3^{\text {a }}$ série do EM. As questóes foram organizadas para compor 3 cadernos diferentes de cada uma das disciplinas.

Participaram da avaliação mais de 11.000 alunos. A tabela 1 fornece a distribuição dos alunos por série/disciplina e regiôes brasileiras.

Tabela 1 - Abrangência por Série e Região

\begin{tabular}{|c|c|c|c|c|c|c|c|}
\hline \multirow{2}{*}{ Região } & \multirow{2}{*}{ Série } & \multicolumn{3}{|c|}{ Língua Portuguesa } & \multicolumn{3}{|c|}{ Matemática } \\
\hline & & Previsto & Presente & $\%$ Faltas & Previsto & Presente & $\%$ Faltas \\
\hline \multirow{3}{*}{$\begin{array}{l}\text { Brasil } \\
\text { total }\end{array}$} & $5^{\circ}$ ano & 3610 & 3534 & 2,11 & 3610 & 3538 & 1,99 \\
\hline & $9^{\circ}$ ano & 4018 & 3880 & 3,43 & 4018 & 3873 & 3,61 \\
\hline & $3^{a}$ série $E M$ & 4238 & 3675 & 13,28 & 4238 & 3685 & 13,05 \\
\hline \multirow{3}{*}{ Norte } & $5^{\circ}$ ano & 647 & 632 & 2,32 & 647 & 632 & 2,32 \\
\hline & $9^{\circ}$ ano & 753 & 728 & 3,32 & 753 & 737 & 2,12 \\
\hline & $3^{a}$ série EM & 781 & 698 & 10,63 & 781 & 688 & 11,91 \\
\hline \multirow{3}{*}{ Nordeste } & $5^{\circ}$ ano & 810 & 792 & 2,22 & 810 & 795 & 1,85 \\
\hline & $9^{\circ}$ ano & 946 & 909 & 3,91 & 946 & 902 & 4,65 \\
\hline & 3a série EM & 1206 & 1054 & 12,60 & 1206 & 1018 & 15,59 \\
\hline \multirow{3}{*}{ Sudeste } & $5^{\circ}$ ano & 1353 & 1329 & 1,77 & 1353 & 1323 & 2,22 \\
\hline & $9^{\circ}$ ano & 1433 & 1374 & 4,12 & 1433 & 1374 & 4,12 \\
\hline & 3a série EM & 1374 & 1150 & 16,30 & 1374 & 1211 & 11,86 \\
\hline \multirow{3}{*}{ Sul } & $5^{\circ}$ ano & 409 & 396 & 3,18 & 409 & 398 & 2,69 \\
\hline & $9^{\circ}$ ano & 450 & 442 & 1,78 & 450 & 437 & 2,89 \\
\hline & $3^{\text {a }}$ série EM & 445 & 407 & 8,54 & 445 & 406 & 8,76 \\
\hline \multirow{3}{*}{$\begin{array}{l}\text { Centro- } \\
\text { Oeste }\end{array}$} & $5^{\circ}$ ano & 391 & 385 & 1,53 & 391 & 390 & 0,26 \\
\hline & $9^{\circ}$ ano & 436 & 427 & 2,06 & 436 & 423 & 2,98 \\
\hline & 3a série EM & 432 & 366 & 15,28 & 432 & 362 & 16,20 \\
\hline
\end{tabular}

\section{RESULTADOS DOS DESEMPENHOS DOS ALUNOS NA AVALIAÇÃO}

Os resultados dos alunos da Fundação Bradesco estão sendo apresentados nas escalas de desempenho do Saeb. Para entender o que os números significam é necessário conhecer o conceito de escalas e como elas são obtidas e interpretadas. 


\subsection{Conceito e Escalas de Desempenho do Saeb}

Uma escala é uma maneira de medir resultados de forma ordenada em que são arbitradas a origem e a unidade de medida. As escalas de proficiências do Saeb ${ }^{1}$ (adotadas na Prova Brasil) ordenam os desempenhos dos alunos do menor para o maior em um continuum.

\subsection{Médias de Desempenho dos Alunos da Fundaçáo Bradesco}

Serão apresentadas as médias dos desempenhos dos alunos da Fundação Bradesco, por série, disciplina e regióes geográficas, tendo como referência os resultados dos alunos brasileiros obtidos nas séries e disciplinas testadas.

\subsubsection{Médias dos alunos brasileiros no Saeb 2005}

A tabela 2 apresenta a média dos alunos por série, considerando o Brasil como um todo, e ainda o resultado da rede particular no Brasil. Tratando-se de uma amostra de alunos, o erro padrão foi incluído.

Os resultados apresentados a seguir referem-se às escolas urbanas, excluindo-se as escolas federais, uma vez que estas existem em poucas unidades da Federaçáo.

Tabela 2 - Médias das Escolas Urbanas - Saeb 2005 -

Língua Portuguesa e Matemática

\begin{tabular}{|c|c|c|c|c|c|c|c|c|c|c|c|c|}
\hline \multirow{3}{*}{ Dependência } & \multicolumn{6}{|c|}{ Língua Portuguesa } & \multicolumn{6}{|c|}{ Matemática } \\
\hline & \multicolumn{2}{|c|}{$5^{\circ}$ ano } & \multicolumn{2}{|c|}{$9^{\circ}$ ano } & \multicolumn{2}{|c|}{$3^{a}$ série EM } & \multicolumn{2}{|c|}{$5^{\circ}$ ano } & \multicolumn{2}{|c|}{$9^{\circ}$ ano } & \multicolumn{2}{|c|}{$3^{a}$ série EM } \\
\hline & Média & EP & Média & EP & Média & EP & Média & EP & Média & EP & Média & EP \\
\hline Brasil Total & 175,5 & $(1,1)$ & 231,7 & $(0,9)$ & 257,1 & $(1,6)$ & 185,7 & $(1,0)$ & 239,4 & $(1,1)$ & 270,7 & $(1,8)$ \\
\hline Brasil Estadual & 173,0 & $(1,4)$ & 226,6 & $(1,5)$ & - & - & 181,8 & $(1,4)$ & 232,9 & $(1,8)$ & - & - \\
\hline Brasil Municipal & 169,0 & $(1,9)$ & 222,5 & $(1,2)$ & - & - & 178,9 & $(1,6)$ & 228,4 & $(1,2)$ & - & - \\
\hline Brasil Est./Mun. & - & - & - & - & 248,7 & $(1,7)$ & - & - & - & - & 260,0 & $(1,7)$ \\
\hline Brasil Particular & 211,6 & $(1,1)$ & 275,5 & $(1,4)$ & 306,9 & $(1,4)$ & 226,4 & $(1,3)$ & 293,5 & $(1,5)$ & 333,3 & $(2,2)$ \\
\hline
\end{tabular}

\subsubsection{Médias dos alunos da Fundação Bradesco, por série e regióes}

$\mathrm{O}$ conjunto de tabelas apresentadas a seguir mostra as médias obtidas pelos alunos, por série/disciplinas. As primeiras tabelas apresentarão esses dados para o Brasil e as regióes brasileiras.

A análise prosseguirá apresentando as tabelas com dados para as unidades da Federação.

\footnotetext{
${ }^{1}$ Para maiores detalhes ver Fontanive e Klein, 2000; Fontanive, 2005 e Klein, 2005.
} 
Para uma avaliação dos resultados, inclui-se na tabela o número de alunos previsto, presentes e o porcentual de faltas, a média da distribuição das proficiências dos alunos, o desvio padrão da distribuição das proficiências e os percentis 5, 25, 50, 75 e 95, além dos valores mínimo e máximo da distribuição das proficiências. Para a melhor compreensão dos resultados é importante saber que:

- Desvio Padráo (DP) é uma medida de dispersão em torno da média da populaçáo e é apresentado para dar uma idéia do espalhamento da distribuição. Em uma distribuição normal o intervalo com extremos a média -2xdp e média $+2 x d p$ abrange $95 \%$ da população.

- Percentil P é um valor tal que P\% as observaçóes são menores ou iguais a esse valor e (1-P)\% as observaçóes sáo maiores ou iguais. Por exemplo, o Percentil 5 é um valor tal que $5 \%$ dos alunos avaliados têm proficiências menor ou igual ao do percentil e $95 \%$ têm proficiência maior ou igual a esse valor.

Tabela 3 - Médias do Desempenho dos Alunos da Fundação Bradesco no Brasil e Regiões - Matemática, $5^{\circ}$ ano

\begin{tabular}{lrrrrrrrrrrrr}
\hline \multicolumn{1}{c}{ Região } & Alu prev & Pres & \% Falta & Média & DP & Min & Perc. 5 & Perc.25 & Perc. 50 & Perc. 75 & Perc. 95 & Máx. \\
\hline Brasil & $\mathbf{3 6 1 0}$ & $\mathbf{3 5 3 8}$ & $\mathbf{1 , 9 9}$ & $\mathbf{2 3 3 , 7 4}$ & $\mathbf{4 4 , 2 0}$ & $\mathbf{9 9 , 6 3}$ & $\mathbf{1 6 5 , 2 5}$ & $\mathbf{2 0 1 , 3 2}$ & $\mathbf{2 3 2 , 3 9}$ & $\mathbf{2 6 4 , \mathbf { 1 8 }}$ & $\mathbf{3 1 7 , 0 9}$ & $\mathbf{3 3 6 , 4 7}$ \\
Norte & 647 & 632 & 2,32 & 217,82 & 43,26 & 102,11 & 156,45 & 186,06 & 211,81 & 246,38 & 294,85 & 336,47 \\
Nordeste & 810 & 795 & 1,85 & 224,24 & 40,26 & 99,63 & 163,81 & 194,43 & 219,68 & 250,76 & 295,57 & 336,47 \\
Sudeste & 1353 & 1323 & 2,22 & 247,60 & 44,28 & 113,15 & 171,99 & 217,17 & 248,63 & 277,88 & 317,09 & 336,47 \\
Sul & 409 & 398 & 2,69 & 240,57 & 40,33 & 133,67 & 173,12 & 212,51 & 239,00 & 270,25 & 308,87 & 336,47 \\
Centro-Oeste & 391 & 390 & 0,26 & 224,90 & 41,54 & 125,28 & 159,20 & 198,30 & 221,98 & 252,95 & 292,14 & 336,47 \\
\hline
\end{tabular}

No $5^{\circ}$ ano, em Matemática e em Língua Portuguesa, vê-se que a média da Região Sudeste é maior do que a média das demais regióes, 247,60 e 231,42, respectivamente.

Analisando-se as proficiências desses alunos nos percentis, constata-se que o percentil 75, em ambas as disciplinas, em todas as regióes, está acima da média brasileira do Saeb 2005.

Observa-se também que as médias dos alunos do $5^{\circ}$ ano, nas regiōes $\mathrm{Sul}$ e $\mathrm{Su}$ deste, estão acima da média obtida pelos alunos, da mesma série, no Saeb - Rede Particular $(226,4)$.

Em Matemática, no $5^{\circ}$ ano, a tabela 3 revela que a Região Sudeste tem médias bem mais altas do que as demais regióes, e, ainda, que a diferença das médias entre a Região Sudeste e a Regiáo Norte é muito grande - 30 pontos na escala, ou seja, mais 
do que meio desvio padrão. Comparativamente às médias brasileiras do Saeb, vê-se que nas Regióes Sudeste e Sul, as médias dos alunos do $5^{\circ}$ ano $(247,60$ e 240,57, respectivamente) são superiores à média brasileira do $9^{\circ}$ ano $(239,4)$.

Tabela 4 - Médias do Desempenho dos Alunos da Fundação Bradesco no Brasil e Regiões - Língua Portuguesa, $5^{\circ}$ ano

\begin{tabular}{lrrrrrrrrrrrr}
\hline \multicolumn{1}{c}{ Região } & Alu prev & Pres & \% Falta & Média & DP & Min & Perc. 5 & Perc.25 & Perc. 50 & Perc. 75 & Perc. 95 & Máx. \\
\hline Brasil & $\mathbf{3 6 1 0}$ & $\mathbf{3 5 3 4}$ & $\mathbf{2 , 1 1}$ & $\mathbf{2 2 1 , 6 8}$ & $\mathbf{4 2 , 0 4}$ & $\mathbf{8 9 , 1 4}$ & $\mathbf{1 5 0 , 5 9}$ & $\mathbf{1 9 2 , 8 7}$ & $\mathbf{2 2 2 , 7 6}$ & $\mathbf{2 5 0 , 7 4}$ & $\mathbf{2 8 8 , 6 7}$ & $\mathbf{3 3 3 , 2 3}$ \\
Norte & 647 & 632 & 2,32 & 207,96 & 39,95 & 102,07 & 142,50 & 180,86 & 208,25 & 233,56 & 275,46 & 322,49 \\
Nordeste & 810 & 792 & 2,22 & 216,48 & 40,07 & 98,43 & 150,14 & 189,14 & 215,20 & 243,62 & 282,30 & 333,23 \\
Sudeste & 1353 & 1329 & 1,77 & 231,42 & 43,02 & 89,15 & 153,35 & 204,06 & 235,79 & 261,74 & 296,24 & 333,23 \\
Sul & 409 & 396 & 3,18 & 225,41 & 37,45 & 89,14 & 165,36 & 202,13 & 226,80 & 249,82 & 288,56 & 322,49 \\
Centro-Oeste & 391 & 385 & 1,53 & 217,47 & 41,90 & 121,92 & 152,26 & 186,21 & 215,99 & 244,47 & 288,64 & 333,23 \\
\hline
\end{tabular}

Os resultados do $9^{\circ}$ ano serão comentados a seguir com os dados das tabelas de desempenho em Língua Portuguesa e em Matemática.

Tabela 5 - Médias do Desempenho dos Alunos da Fundação Bradesco no Brasil e Regiões - Matemática, $9^{\circ}$ ano

\begin{tabular}{lrrrrrrrrrrrr}
\hline \multicolumn{1}{c}{ Região } & Alu prev & Pres & \% Falta & Média & DP & Min & Perc. 5 & Perc.25 & Perc. 50 & Perc. 75 & Perc. 95 & Máx. \\
\hline Brasil & $\mathbf{4 0 1 8}$ & $\mathbf{3 8 7 3}$ & $\mathbf{3 , 6 1}$ & $\mathbf{2 9 2 , 5 1}$ & $\mathbf{4 3 , 5 8}$ & $\mathbf{1 5 6 , 5 0}$ & $\mathbf{2 1 9 , 5 0}$ & $\mathbf{2 6 2 , 7 7}$ & $\mathbf{2 9 2 , 5 7}$ & $\mathbf{3 2 2 , 0 8}$ & $\mathbf{3 6 5 , 8 6}$ & $\mathbf{4 1 2 , 2 6}$ \\
Norte & 753 & 737 & 2,12 & 274,00 & 43,04 & 164,29 & 207,44 & 244,01 & 271,73 & 303,94 & 349,82 & 412,26 \\
Nordeste & 946 & 902 & 4,65 & 290,80 & 44,98 & 156,50 & 214,69 & 261,98 & 291,28 & 320,45 & 369,12 & 412,26 \\
Sudeste & 1433 & 1374 & 4,12 & 302,47 & 41,43 & 180,71 & 234,66 & 275,00 & 302,54 & 332,10 & 370,35 & 412,26 \\
Sul & 450 & 437 & 2,89 & 297,09 & 40,69 & 160,46 & 228,00 & 268,68 & 297,75 & 325,05 & 360,54 & 398,08 \\
Centro-Oeste & 436 & 423 & 2,98 & 291,36 & 40,35 & 173,73 & 223,73 & 263,76 & 292,56 & 319,24 & 355,71 & 412,26 \\
\hline
\end{tabular}

A média brasileira em Matemática é 239,4 e nota-se que a Fundação Bradesco apresenta média superior a esta em todas as regióes. Quando comparadas com a média obtida pelas escolas particulares do Saeb $(293,5)$, somente 2 regióes - Sudeste e Sul - ultrapassam essa média (302,47 e 297,09, respectivamente).

Tabela 6 - Médias do Desempenho dos Alunos da Fundação Bradesco no Brasil e Regiões - Língua Portuguesa, $9^{\circ}$ ano

\begin{tabular}{lrrrrrrrrrrrr}
\hline \multicolumn{1}{c}{ Região } & Alu prev & Pres & \% Falta & Média & DP & Min & Perc. 5 & Perc.25 & Perc. 50 & Perc. 75 & Perc. 95 & Máx. \\
\hline Brasil & $\mathbf{4 0 1 8}$ & $\mathbf{3 8 8 0}$ & $\mathbf{3 , 4 3}$ & $\mathbf{2 7 2 , 0 9}$ & $\mathbf{4 1 , 0 3}$ & $\mathbf{1 3 0 , 2 5}$ & $\mathbf{1 9 9 , 7 5}$ & $\mathbf{2 4 4 , 8 1}$ & $\mathbf{2 7 4 , 9 0}$ & $\mathbf{3 0 1 , 1 5}$ & $\mathbf{3 3 5 , 4 6}$ & $\mathbf{3 8 3 , 6 6}$ \\
Norte & $\mathbf{3 5}$ & $\mathbf{7 2 8}$ & 3,32 & 255,24 & 39,46 & 147,95 & 190,46 & 227,73 & 255,49 & $\mathbf{2 8 2 , 2 2}$ & 321,91 & 362,05 \\
Nordeste & 946 & 909 & 3,91 & 267,67 & 39,96 & 142,18 & 198,77 & 241,05 & 270,66 & 297,44 & 329,20 & 383,66 \\
Sudeste & 1433 & 1374 & 4,12 & 282,98 & 39,77 & 151,71 & 211,98 & 256,90 & 285,22 & 311,87 & 342,63 & 383,66 \\
Sul & 450 & 442 & 1,78 & 273,19 & 39,99 & 130,25 & 201,16 & 247,97 & 275,34 & 300,63 & 336,30 & 383,66 \\
Centro-Oeste & 436 & 427 & 2,06 & 274,01 & 40,04 & 152,55 & 203,49 & 249,38 & 278,29 & 301,19 & 332,88 & 366,67 \\
\hline
\end{tabular}


Em Língua Portuguesa, as médias de todas as regiôes são superiores à média brasileira no Saeb, embora, somente a Região Sudeste apresente média superior $(282,98)$ à das escolas particulares no Saeb $(275,5)$. A tabela 6 também mostra que a Região Norte foi a que teve o pior desempenho.

Tabela 7 - Médias do Desempenho dos Alunos da Fundação Bradesco no Brasil e Regiões - Matemática, $3^{\text {a }}$ série EM

\begin{tabular}{lrrrrrrrrrrrr}
\hline \multicolumn{1}{c}{ Região } & Alu prev & Pres & \% Falta & Média & DP & Min & Perc. 5 & Perc.25 & Perc. 50 & Perc. 75 & Perc. 95 & Máx. \\
\hline Brasil & $\mathbf{4 2 3 8}$ & $\mathbf{3 6 8 5}$ & $\mathbf{1 3 , 0 5}$ & $\mathbf{3 0 8 , 0 7}$ & $\mathbf{4 4 , 6 7}$ & $\mathbf{1 8 0 , 4 8}$ & $\mathbf{2 3 5 , 8 1}$ & $\mathbf{2 7 6 , 9 0}$ & $\mathbf{3 0 7 , 1 0}$ & $\mathbf{3 4 1 , 7 3}$ & $\mathbf{3 7 8 , 2 1}$ & $\mathbf{4 5 7 , 5 3}$ \\
Norte & $\mathbf{3 1}$ & 688 & 11,91 & 294,89 & 41,36 & 180,84 & 230,71 & 266,29 & 291,07 & 326,17 & 361,61 & 406,89 \\
Nordeste & 1206 & 1018 & 15,59 & 303,64 & 46,16 & 180,48 & 230,40 & 270,44 & 302,05 & 337,05 & 377,92 & 457,53 \\
Sudeste & 1374 & 1211 & 11,86 & 316,08 & 42,62 & 181,41 & 247,50 & 286,14 & 315,82 & 347,22 & 381,92 & 444,16 \\
Sul & 445 & 406 & 8,76 & 316,26 & 43,10 & 184,46 & 247,61 & 284,74 & 317,56 & 347,75 & 376,79 & 449,94 \\
Centro-Oeste & 432 & 362 & 16,20 & 309,62 & 47,46 & 203,03 & 234,18 & 272,86 & 308,48 & 349,99 & 379,02 & 410,14 \\
\hline
\end{tabular}

A média brasileira no Saeb, em Matemática, na $3^{a}$ série do EM, é 270,7 e vêse que os alunos da Fundação Bradesco, em todas as regióes, apresentam médias bem superiores às do Saeb. Entretanto, em nenhuma região a média da Fundação Bradesco é maior do que a alcançada pelos alunos das escolas particulares avaliados pelo Saeb $(333,3)$. Esse resultado é, portanto, aquém do esperado para a série e bem inferior aos apresentados pelos alunos do $5^{\circ}$ e $9^{\circ}$ anos do EF, quando comparados aos obtidos pelos alunos das escolas particulares no Saeb.

Tabela 8 - Médias do Desempenho dos Alunos da Fundação Bradesco no Brasil e Regiões - Língua Portuguesa, $3^{\text {a }}$ série EM

\begin{tabular}{|c|c|c|c|c|c|c|c|c|c|c|c|c|}
\hline Região & Alu prev & Pres & $\%$ Falta & Média & DP & Min & Perc. 5 & Perc.25 & Perc. 50 & Perc. 75 & Perc. 95 & Máx. \\
\hline Brasil & 4238 & 3675 & 13,28 & 306,66 & 42,56 & 147,83 & 231,14 & 279,68 & 310,85 & 336,49 & 370,32 & 420,6 \\
\hline Norte & 81 & 698 & 10,63 & 297,22 & 42,22 & 161,53 & 221,05 & 271,53 & 301,34 & 326,62 & 358,18 & 420,6 \\
\hline Nordeste & 1206 & 1054 & 12,60 & 301,85 & 42,60 & 147,83 & 223,41 & 274,31 & 305,84 & 331,99 & 365,69 & 408,63 \\
\hline Sudeste & 1374 & 1150 & 16,30 & 316,88 & 41,62 & 162,31 & 238,61 & 291,56 & 320,56 & 346,12 & 378,06 & 420,6 \\
\hline Sul & 445 & 407 & 8,54 & 307,33 & 39,78 & 179,60 & 244,85 & 280,18 & 307,81 & 335,37 & 372,67 & 420,61 \\
\hline Centro-Oeste & 432 & 366 & 15,28 & 305,65 & 42,56 & 179,98 & 230,52 & 275,38 & 309,38 & 336,17 & 370,29 & 407,8 \\
\hline
\end{tabular}

Os resultados de Língua Portuguesa são melhores que os obtidos em Matemática, pois em Língua Portuguesa os alunos da Fundação Bradesco têm média igual à dos alunos das escolas particulares no Brasil, e em 2 regióes as médias ultrapassam as obtidas pelos alunos das escolas particulares no Saeb $(306,09)$, a saber: Regiáo Sudeste $(316,88)$, Região Sul $(307,33)$. 


\section{DESEMPENHO DOS ALUNOS DA FUNDAÇÃO BRADESCO EM RELAÇÃO ÀS METAS DO COMPROMISSO TODOS PELA EDUCAÇÃO}

O Movimento Compromisso Todos pela Educação congrega parcerias entre a sociedade civil, iniciativa privada, organizaçóes sociais, educadores e gestores públicos da educação. Ele tem como objetivo garantir a Educação Básica de qualidade para todos os brasileiros até 2022, ano do bicentenário da Independência do Brasil. O Movimento estabelece 5 metas, e entre elas a meta 3 que diz que todo aluno deve ter um aprendizado adequado à sua série. A meta foi quantificada para que no ano de 2022 mais de 70\% dos alunos tenham proficiências acima dos seguintes níveis da escala do Saeb:

Tabela 9 - Níveis de proficiência do Saeb a serem atingidos por 70\% dos alunos brasileiros até 2022 (Meta 3 do Compromisso Todos pela Educação)

\begin{tabular}{lcc}
\hline Ano/Série & Língua Portuguesa & Matemática \\
\hline $5^{\circ}$ ano/4 & 200 & 225 \\
$9^{\circ}$ ano $/ 8^{\text {a }}$ série & 275 & 300 \\
$3^{\text {a }}$ série do EM & 300 & 350 \\
\hline
\end{tabular}

Os porcentuais dos alunos da Fundação Bradesco acima desses níveis em cada série são apresentados a seguir.

Tabela 10 - Porcentual de alunos da Fundação Bradesco acima dos níveis recomendados na tabela 9, em 2007

\begin{tabular}{lcc}
\hline Ano/Série & Língua Portuguesa & Matemática \\
\hline $5^{\circ}$ ano/4 & 69,9 & 55,5 \\
$9^{\circ}$ ano $/ 8^{\text {a }}$ série & 49,9 & 43,9 \\
$3^{\text {a }}$ série do EM & 59,7 & 19,1 \\
\hline
\end{tabular}

Em Língua Portuguesa os alunos do $5^{\circ}$ ano da Fundação Bradesco praticamente alcançaram a meta, e, em Matemática, há necessidade de melhoria para atingi-la. Nas outras séries, nota-se que há espaço para crescer em direção às metas, especialmente em Matemática na $3^{a}$ série do EM.

\section{PERFIL DOS ALUNOS DA FUNDAÇÃO BRADESCO}

Os resultados das pesquisas educacionais vêm mostrando uma associação positiva entre o desempenho dos alunos, medido por testes de escolaridade, e o nível socioeconômico e cultural dos alunos e suas famílias. As pesquisas voltadas para avaliar o efeito da escola na aprendizagem procuram controlar os resultados por variáveis socioeconômicas, de modo a relativizar certos resultados encontrados. 
Para o estudo do perfil dos alunos da Fundação Bradesco, foram selecionadas as variáveis demográficas: sexo, como os alunos se consideram em relação à cor e idade. As tabelas 11, 12 e 13 apresentam esses resultados.

Tabela 11 - Porcentual de Alunos da Fundação Bradesco por Sexo

\begin{tabular}{lccc}
\hline Sexo & $\mathbf{5}^{\mathbf{a}}$ ano & $\mathbf{9}^{\circ}$ ano & $\mathbf{3}^{\text {a }}$ série EM \\
\hline Masculino & 49,9 & 47,3 & 44,4 \\
Feminino & 49,9 & 52,7 & 55,6 \\
\hline
\end{tabular}

Observa-se, na tabela 11 , que o porcentual de alunos de ambos os sexos, no $5^{\circ}$ ano, é o mesmo. No entanto, no $9^{\circ}$ ano o porcentual do sexo feminino é maior e aumenta ainda mais na $3^{\text {a }}$ série do Ensino Médio. Esse fato é observado também no Brasil, onde, no Saeb 2007, os porcentuais observados para o sexo masculino e feminino são, respectivamente, $45,3 \%$ e $52,7 \%$ no $9^{\circ}$ ano e $41,2 \%$ e $57,2 \%$ na $3^{a}$ série do EM.

$\mathrm{Na}$ Fundação Bradesco, em todas as séries, predominam alunos que se declaram pardos. Pode-se ver também que o porcentual dos que se declararam pretos aumenta com a progressão escolar, enquanto o porcentual dos que se declaram pardos diminui.

Tabela 12 - Porcentual de Alunos da Fundação Bradesco em relação à Cor Declarada

\begin{tabular}{lccc}
\hline $\begin{array}{l}\text { Como se considera } \\
\text { em relação à cor }\end{array}$ & $\mathbf{5}^{\mathbf{0}}$ ano & $\mathbf{9}^{\mathbf{0}}$ ano & $\mathbf{3}^{\mathbf{a}}$ série EM \\
\hline Branco & 37,7 & 37,0 & 39,7 \\
Pardo & 47,9 & 42,8 & 42,7 \\
Preto & 6,8 & 10,6 & 11,4 \\
Amarelo & 2,4 & 5,3 & 4,8 \\
Indígena & 4,7 & 4,0 & 1,1 \\
\hline
\end{tabular}

Em geral, no Brasil, os dados do Saeb revelam que existe um aumento do porcentual de alunos que se declaram brancos com a progressáo escolar, evidenciando certo grau de exclusão social, o que não ocorre na Fundação Bradesco. 
Tabela 13 - Porcentual de Alunos da Fundação Bradesco por Idade e Série/Ano

\begin{tabular}{cccc}
\hline Idade & $\mathbf{5}^{\mathbf{a}}$ ano & $\mathbf{9}^{\mathbf{0}}$ ano & $\mathbf{3}^{\mathbf{a}}$ série EM \\
\hline 7 anos & 0,0 & - & - \\
8 anos & 0,6 & - & - \\
9 anos & 9,5 & - & - \\
10 anos & 76,8 & - & - \\
11 anos & 10,6 & - & - \\
12 anos & 2,3 & 0,2 & - \\
13 anos & 0,2 & 11,4 & - \\
14 anos & - & 73,1 & 0,0 \\
15 anos & - & 12,3 & 0,6 \\
16 anos & - & 2,5 & 13,1 \\
17 anos & - & 0,3 & 67,4 \\
18 anos & - & - & 14,6 \\
19 anos & - & 0,1 & 3,4 \\
20 anos & - & 0,1 & 0,8 \\
21 anos & - & - & 0,1 \\
22 anos & - & - & 0,1 \\
\hline
\end{tabular}

Em relação à defasagem, na Fundação Bradesco, no $5^{\circ}$ ano, somente $13 \%$ dos alunos estão nessa situação, considerando a idade correta de 10 anos. Esse porcentual sobe para $15 \%$ no $9^{\circ}$ ano e para $19 \%$ na $3^{\text {a }}$ série do EM, mostrando que - embora em proporções bem menores que no Brasil - a defasagem, na Fundação Bradesco, também é maior à medida que a série/ano aumenta.

Tabela 14 - Porcentual de Alunos por Nível Socioeconômico Brasil e Regiões, $5^{\circ}$ ano, $9^{\text {a }}$ ano e $3^{\text {a }}$ Série EM

\begin{tabular}{|c|c|c|c|c|c|c|c|c|c|c|c|c|c|c|c|}
\hline \multirow{3}{*}{ Região } & \multicolumn{5}{|c|}{$5^{\circ}$ ano } & \multicolumn{5}{|c|}{$9^{\circ}$ ano } & \multicolumn{5}{|c|}{ 3a série EM } \\
\hline & \multicolumn{5}{|c|}{ Classe } & \multicolumn{5}{|c|}{ Classe } & \multicolumn{5}{|c|}{ Classe } \\
\hline & A & B & C & D & $\mathbf{E}$ & A & B & C & D & $\mathbf{E}$ & A & B & C & D & $\mathbf{E}$ \\
\hline Brasil & 7,1 & 37,4 & 44,6 & 10,0 & 0,9 & 7,4 & 37,3 & 46,9 & 7,9 & 0,6 & 4,6 & 30,0 & 52,1 & 12,7 & 0,5 \\
\hline Norte & 3,0 & 28,3 & 48,3 & 16,9 & 3,5 & 1,1 & 28,2 & 54,1 & 14,1 & 2,5 & 0,9 & 20,3 & 59,6 & 17,5 & 1,6 \\
\hline Nordeste & 0,9 & 23,9 & 59,8 & 15,1 & 0,4 & 1,6 & 23,9 & 64,1 & 10,0 & 0,4 & 0,5 & 12,6 & 65,8 & 20,9 & 0,2 \\
\hline Sudeste & 14,6 & 48,6 & 31,0 & 5,6 & 0,2 & 17,1 & 48,0 & 30,3 & 4,6 & 0,0 & 11,7 & 46,0 & 37,2 & 4,9 & 0,2 \\
\hline Sul & 4,8 & 44,1 & 45,8 & 5,1 & 0,3 & 3,2 & 52,1 & 41,2 & 3,5 & 0,0 & 2,2 & 44,4 & 47,9 & 5,5 & 0,0 \\
\hline Centro-Oeste & 3,4 & 34,3 & 52,8 & 9,0 & 0,5 & 2,9 & 31,1 & 57,4 & 8,4 & 0,2 & 2,0 & 28,5 & 53,6 & 14,8 & 1,1 \\
\hline
\end{tabular}

Para a análise do perfil socioeconômico dos alunos avaliados na Fundação Bradesco foi utilizado o índice do Critério Brasil, que é baseado na posse de bens e no nível de escolaridade dos pais. Esse índice pode ser também calculado para os alunos brasileiros avaliados no Saeb e na Prova Brasil.

Os dados da tabela 14 foram adaptados do Critério Brasil, cuja composição original está no anexo. No Critério Brasil a soma de pontos é 34 enquanto na 
Avaliação da Fundação Bradesco a soma é de 29 pontos, pois houve cortes na pontuação máxima de alguns bens, como, por exemplo, nos números de rádios, televisores a cores e automóveis. Entretanto, foram utilizados os mesmos pontos de corte, pois esse número maior de bens só afeta o índice das classes sociais mais altas.

A tabela mostra um perfil do alunado diferente do perfil da população brasileira segundo o Critério Brasil. Os porcentuais de alunos nas classes D e E na Fundação Bradesco são de $10 \%$ e $0,9 \%$, no $5^{\circ}$ ano, enquanto nas escolas públicas no Brasil, em 2007, esses porcentuais são de $16,7 \%$ e 1,3\%, respectivamente, evidenciando que a população brasileira é um pouco mais pobre.

Observa-se também na Fundação Bradesco, como no Brasil, diferenças nos perfis socioeconômicos dos alunos nas regióes brasileiras. Enquanto na Região Sudeste, no $5^{\circ}$ ano, $63 \%$ dos seus alunos pertencem às classes $A$ e $B$, na Região Norte esse percentual é de somente $31 \%$, evidenciando que, como no Brasil, em todas as séries, as distribuiçóes nas Regiôes Norte e Nordeste mostram um quadro de menor condição socioeconômica dos alunos do que nas Regióes Sul e Sudeste.

Analisando-se os dados da $3^{\text {a }}$ série do EM, nota-se que o porcentual de alunos nas classes A e B (35\%) é menor que nos $5^{\circ}$ e $9^{\circ}$ anos (cerca de $44 \%$ em ambos).

A apuração das respostas dos questionários dos professores e diretores das escolas da Fundação Bradesco não trouxe contribuiçóes relevantes para diferenciar os desempenhos obtidos em relaçáo a práticas pedagógicas, atitudes, estilos de gestáo, pois houve muito pouca variabilidade de respostas, em parte em razão do pequeno número de respondentes e também de critérios comuns de seleção e permanência de professores e diretores.

Foram realizadas também análises de regressão multiníveis, procurando explicar o desempenho em virtude de variáveis socioeconômicas e culturais.

Neste artigo, entretanto, serão apresentadas somente relações entre a média das proficiências de cada turma e a média do nível socioeconômico (NSE), medido pelo valor numérico do Critério Brasil em vez do uso das classes $A, B, C, D$ e E.

Os gráficos de dispersão e a reta da regressão por mínimos quadrados da média de proficiência em relação à média do NSE são apresentados a seguir para cada série/disciplina.

Nota-se que existe uma relaçáo linear crescente positiva entre a média da proficiência e a média do NSE, tanto em língua portuguesa quanto em matemática, ou seja, quanto maior o NSE maior a média da proficiência dos alunos da Fundaçáo 
Bradesco, uma relação encontrada em todas as pesquisas educacionais que estudam o impacto da escola no desempenho dos alunos.

Os gráficos também mostram que há muita variabilidade de desempenho em turmas com níveis socioeconômicos similares, sugerindo que há espaço para intervençôes pedagógicas mais efetivas para aumentar os níveis de proficiências das turmas com mais baixo desempenho. Esses gráficos, com as turmas devidamente identificadas foram apresentados à direção da Fundação Bradesco com a intenção de ajudá-la a adotar as medidas pertinentes.

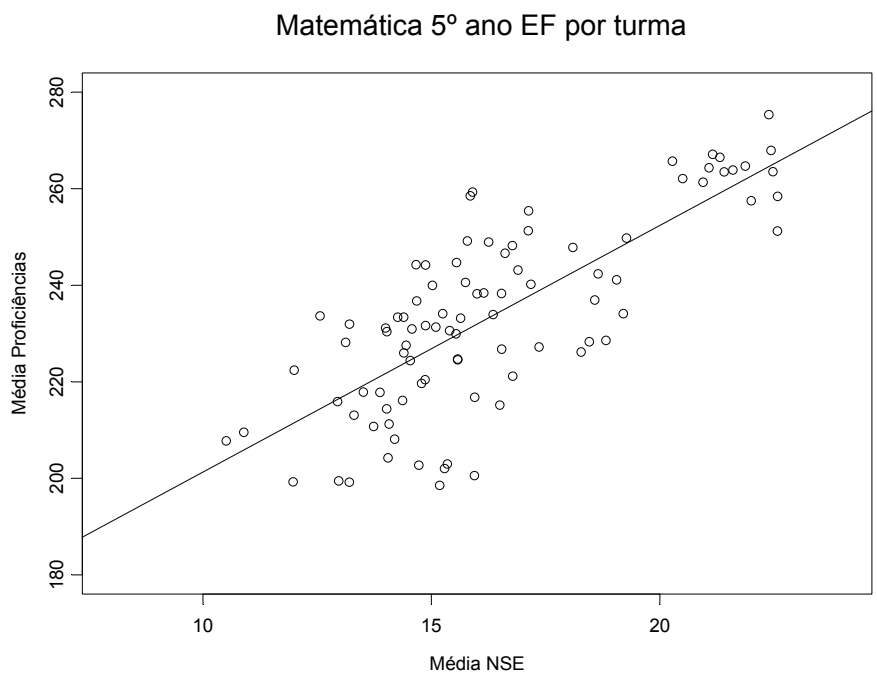

Língua Portuguesa $5^{\circ}$ ano EF por turma

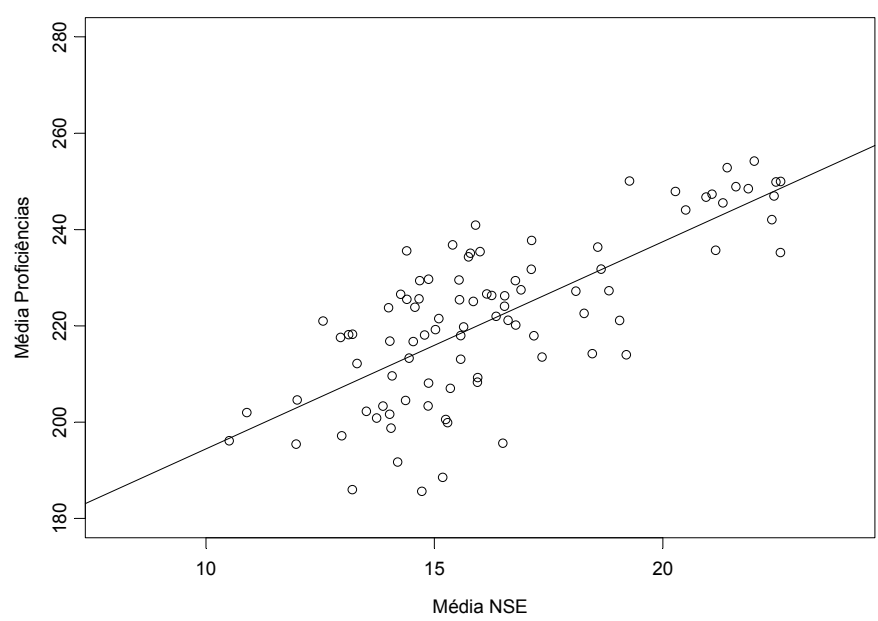


Matemática $9^{\circ}$ ano EF por turma

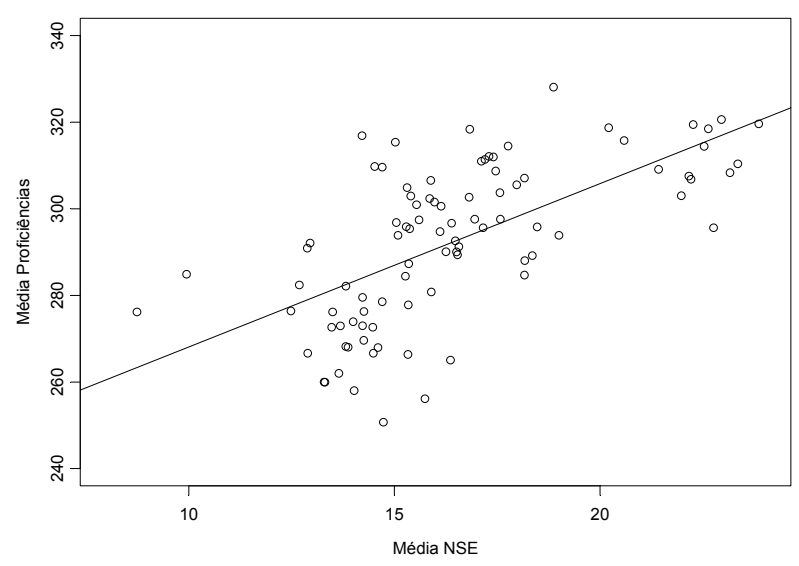

Língua Portuguesa $9^{\circ}$ ano EF por turma

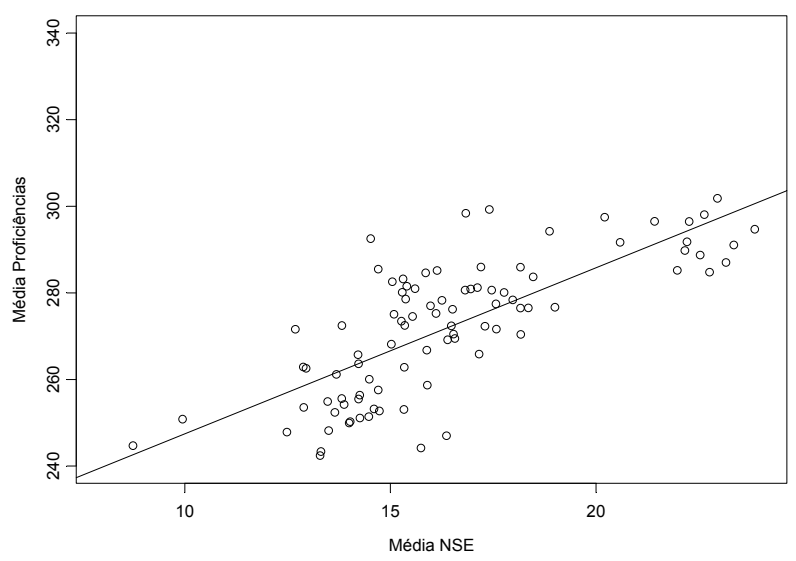

Matemática $3^{a}$ série EM por turma

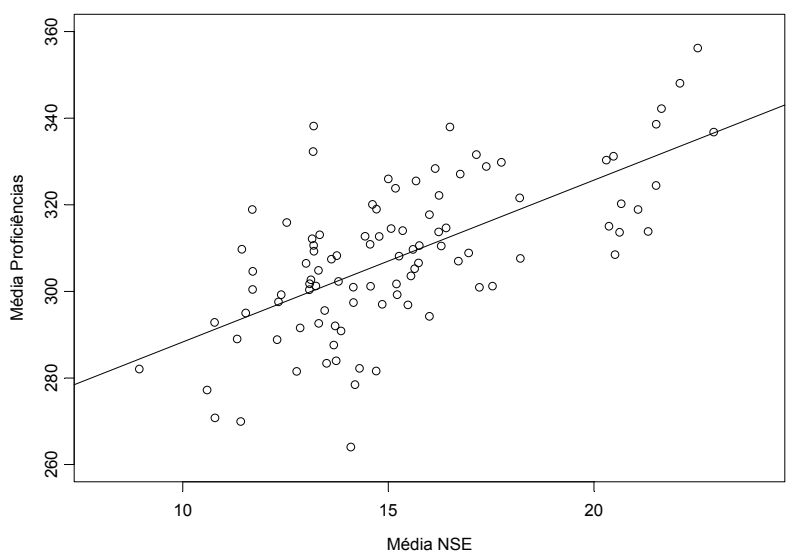




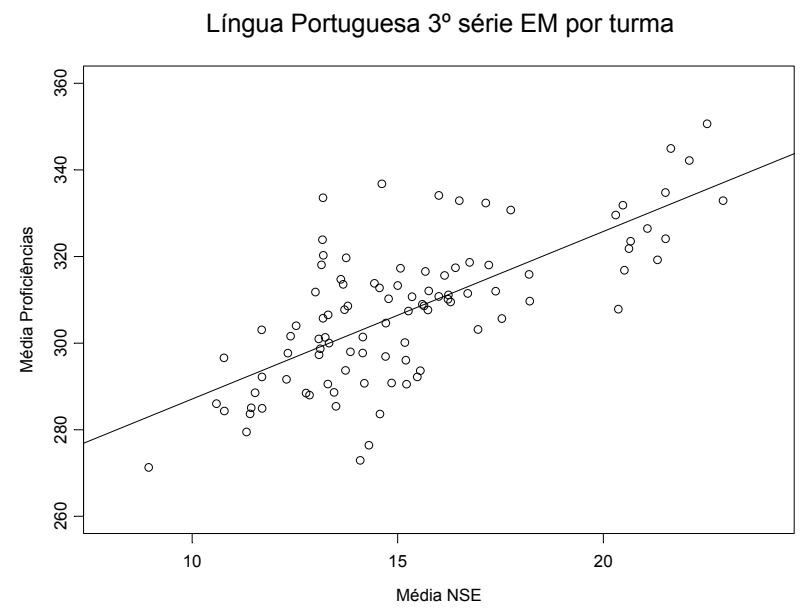

\section{CONCLUSÃO}

Em resumo, a Fundaçáo Bradesco, apesar de atender a clientela de níveis socioeconômicos similares aos dos alunos das escolas públicas brasileiras e bastante diferentes dos perfis dos alunos das escolas particulares, obtém melhores resultados de aprendizagem. Mesmo nas turmas de mais baixo desempenho, as médias são maiores do que as médias dos alunos brasileiros para as mesmas séries/disciplinas, em comparação aos resultados do Saeb.

Deve-se considerar, entretanto, que fatores de eficácia escolar, como a autonomia de gestão financeira, de material e de seleção e substituição dos professores e diretores, estão presentes na Fundação Bradesco.

\section{REFERÊNCIAS BIBLIOGRÁFICAS}

ABEP. Dados com base no levantamento socioeconômico - 2000 - lbope. Disponível em: <http://www.abep.org/codigosguias//ABEP_ CCEB.pdf.>

BROOKE, N.; SOARES, J. F. (Org.). Pesquisa em eficácia escolar: origem e trajetórias. Belo Horizonte: EdUFMG, 2008.

FONTANIVE, Nilma Santos. O Uso pedagógico dos testes. In: SOUZA, Alberto de Mello e (Org.). Dimensões da avaliação educacional. Petrópolis: Vozes, 2005. p. 139-173.
FONTANIVE, N. S.; KLEIN, R. Uma visão sobre o sistema de avaliação da educação básica do Brasil - SAEB. Ensaio: Avaliação e Políticas Públicas em Educação, v.8, n.29, p. 409-442, 2000.

KLEIN, Ruben. Testes de rendimento escolar. In: SOUZA, Alberto de Mello e (Org.). Dimensões da avaliação educacional. Petrópolis: Vozes, 2005. .Como está a educação no Brasil? O que fazer? Ensaio: Avaliação e Políticas Públicas em Educação, v.14, n.51, p. 139-172, 2006.

Recebido em: outubro 2008

Aprovado para publicação em: novembro 2008 
ANEXO: CRITÉRIO BRASIL

Posse de itens

\begin{tabular}{llllll} 
& \multicolumn{5}{c}{ Quantidade de Itens } \\
& 0 & 1 & 2 & 3 & 4 ou + \\
\hline Televisão em cores & 0 & 2 & 3 & 4 & 5 \\
Rádio & 0 & 1 & 2 & 3 & 4 \\
Banheiro & 0 & 2 & 3 & 4 & 4 \\
Automóvel & 0 & 2 & 4 & 5 & 5 \\
Empregada mensalista & 0 & 2 & 4 & 4 & 4 \\
Aspirador de pó & 0 & 1 & 1 & 1 & 1 \\
Máquina de lavar & 0 & 1 & 1 & 1 & 1 \\
Videocassete elou DVD & 0 & 2 & 2 & 2 & 2 \\
$\begin{array}{l}\text { Geladeira } \\
\text { Freezer (aparelho independente } \\
\text { ou parte da geladeira duplex) }\end{array}$ & 0 & 2 & 2 & 2 & 2 \\
\hline
\end{tabular}

\section{Grau de Instructio do chefe de tamilla}

Analfabeto / Primário incompleto

Prim ário completo / Ginasial incompleto

Ginasial completo / Colegial incompleto

Colegial completo / Superior incompleto

superior completo

0

1

2

3

5

\section{CORTES DO CRTEÉRIO BRASIL}

\begin{tabular}{|ccc|}
\hline Classe & PONTOS & TOTAL BRASIL $(\%)$ \\
\hline A1 & $30-34$ & 1 \\
\hline A2 & $25-29$ & 5 \\
\hline B1 & $21-24$ & 9 \\
\hline B2 & $17-20$ & 14 \\
\hline C & $11-16$ & 36 \\
\hline D & $6-10$ & 31 \\
\hline E & $0-5$ & 4 \\
\hline
\end{tabular}

Fonte: Abep, 2003. 